\title{
Editorial: UFSC Integration to The Academic Society Journal
}

\author{
Bock EGP $\ddagger$ Ponce DA§ and Martins D* \\ $\$$ Laboratory of Bioengineering and Biomaterials, Federal Institute of Sao Paulo, Brazil. \\ $\S$ Federal University of Santa Catarina, Campus Blumenau, Brazil. \\ * Federal University of Santa Catarina, Campus Florianópolis, Brazil.
}

Editorial. In this edition, we are pleased to present the last advances of The Academic Society Journal in terms of relevance and diffusion. Due to our continuous effort for improvement, we now have ISSN, DOI in publications, a peer review policy and editorial board of renowned professionals. In this context, our editorial board is integrating professor Daniel Martins, who is coordinator of the Robotics Laboratory (LAR) at UFSC. In addition to him, other LAR members were invited to join the team of reviewers.

The UFSC - IFSP partnership started at 2014, with the approval of CAPES Public Call in Assistive Technology in Brazil and Studies on Disability (PGPTA) No.59/2014 with the project "Reconfigurable Platform for Assistive Technology for Bedridden Patients". The funds from this project helped to finance scholarships for undergraduate and graduate students from both universities involved.

From that moment, UFSC has been participating annually in the MEC3F Congress of Engineering and Applied Sciences in the three Borders, an event that undoubtedly promoted the exchange between these universities. This event is deeply connected with our Society and TAS Journal.

During the 6th International Symposium on Multibody Systems and Mechatronics MuSMe 2017, organized by the Commission for Mechatronics and Technical Committees for Multibody Dynamics, Robotics and Mechatronics in UFSC, in Florianópolis, it became evident the importance of creating research centers of excellence in Latin America to increase our international competitiveness, a fact that we can evidence now with the recent participation of Prof. Silvina Ramos group.

In September 2018, the 4th WMRD - Fourth Workshop on Mechanism and Robot Design, of Federal University of Santa Catarina UFSC was gathered in Blumenau and the participants had the opportunity to discuss new forms of scientific cooperation between the institutions. 


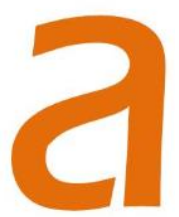

Today, we have completed our partnership with the participation of professors and students from the Robotics Laboratory - LAR from UFSC.

We hope our work and partnership will allow us to further elevate the concept of the TASJ journal, generating a greater impact factor, number of publications and will support scientific and technological knowledge.

Interestingly, what started with assistive technology and accessibility projects can then increase accessibility to scientific publication, open access and free of charges.

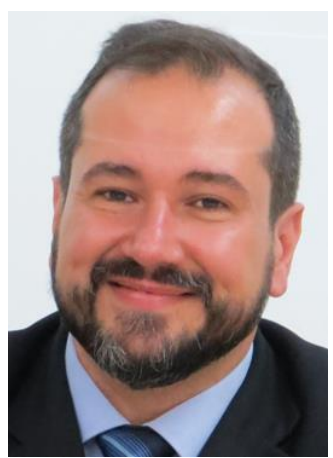

Eduardo Bock

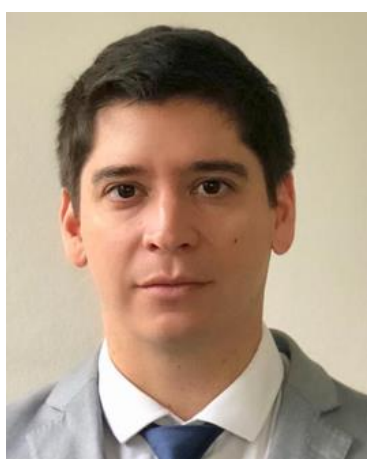

Daniel Ponce

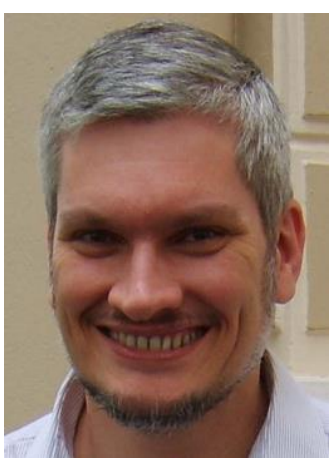

Daniel Martins

Santa Catarina, September $30^{\text {st }} 2020$. 